\title{
ANOREXIA AND SEVERE INANITION ASSOCIATED WITH A TUMOUR INVOLVING THE HYPOTHALAMUS
}

\author{
BY \\ HELEN KAGAN \\ Paedriatric Service, Bikur Holim Hospital, Jerusalem, Israel
}

(RECEIVED FOR PUBLICATION SEPTEMBER 4, 1957)

Anorexia in childhood is a common complaint, resulting as a rule from infectious processes, systemic diseases, metabolic disturbances, or, in healthy children, from quantitative or qualitative overfeeding. There are, however, occasional cases in which none of the above-mentioned factors can be held responsible.

The purpose of this paper is to report the case of an infant suffering from obstinate anorexia since birth, which subsequently proved to be related to a hypothalamic lesion.

\section{Case Report}

E.B., a 3-months-old female baby of Turkish-Jewish parentage, was admitted to the Paediatric Service of the Bikur Holim Hospital on November 3, 1955. The parents who were not related were in good health, as was an older sister, aged $2 \frac{1}{2}$ years. The baby was delivered at full term after an uneventful pregnancy, weighing $3,200 \mathrm{~kg}$. The baby was breast-fed, the feed being supplemented by a cow's milk formula. From birth onwards it had a very poor appetite; it took both the breast and the bottle most unwillingly and in small amounts, and occasionally vomited. Its weight remained practically stationary. The child behaved normally, smiling and taking some interest in its surroundings.

State on Admission. The infant looked emaciated (weight $3,400 \mathrm{~kg}$.), but it smiled readily and followed light. The head was symmetrical and had a circumference of $37 \mathrm{~cm}$. The anterior fontanelle measured $3 \times 2 \cdot 5 \mathrm{~cm}$. and was somewhat depressed. The visceral organs were without abnormalities, except for a right-sided hernia. The neurological and ocular examinations were negative. Body temperature was normal.

Laboratory Examinations. Analysis of the urine was negative. Results of a blood count were as follows : red blood cells, 4,200,000 (haemoglobin, $10.0 \mathrm{~g}$. per $100 \mathrm{ml}$.), white blood cells, 8,400 (segmented neutrophils $34 \%$, rod-shaped neutrophils $4 \%$, eosinophils $1 \%$, monocytes $4 \%$, lymphocytes $58 \%$ ); blood chemistry showed: urea $29 \mathrm{mg}$. $\%$, sugar $98 \mathrm{mg}$. $\%$, calcium $9.4 \mathrm{mg}$. $\%$, $\mathrm{NaCl} 671 \mathrm{mg}$. $\%$ ); total proteins $6.8 \%$ (albumin $4 \cdot 5 \%$, globulin $2 \cdot 3 \%$ ), $\mathrm{CO}_{2}$ combining power was 52 vol. \%; liver function tests were negative. A Mantoux text $(1: 1,000)$ was negative. Paper chromatography of the urine showed a normal amino-acid pattern. The stools were of normal colour and consistency; they were negative for parasites and ova. The duodenal juice contained trypsin.

Radiographic examinations of the chest, stomach and duodenum gave negative results.

In view of the child's poor appetite it was fed seven times a day. Yet, throughout its stay in hospital, it fed very poorly and vomited once or twice a day.

There were, however, a few periods lasting from three to seven days during which there was no vomiting. No appreciable weight gain occurred, the child weighing $3,550 \mathrm{~kg}$. on December 12.

Thirty-nine days after the child's admission (December 12), vertical, horizontal and rotating nystagmus were suddenly noted. As far as could be ascertained no other abnormalities referrable to the central nervous system were present. On December 24, the fontanelle had become tense, bulging and was enlarged to $5.5 \times 5 \mathrm{~cm}$. The baby's eyes had by then the typical 'setting sun' appearance. A lumbar puncture yielded a transparent fluid which contained 11 leucocytes per c.mm. and had a pressure of $220 \mathrm{~mm}$. A Pandy's test showed sugar $53 \mathrm{mg} . \%, \mathrm{NaCl} 827 \mathrm{mg}$. \%. A pneumoencephalogram performed on December 28 showed that both lateral ventricles were markedly enlarged. The pressure of the cerebrospinal fluid at that date was $330 \mathrm{~mm}$. and the reaction to Pandy's test was ++ . The head circumference had increased to $41 \mathrm{~cm}$. and the fronto-occipital diameter was $17 \mathrm{~cm}$. A diagnosis of a communicating hydrocephalus was made and the child was transferred to the neurosurgical department of the Hebrew University-Hadassah Medical School.

On January 23, 1956, Dr. E. Peiser operated on the baby. After resection of the 5th lumbar vertebral arch, an anastomosis between the subarachnoidal space and the peritoneal cavity was performed with a partial removal of the omentum.

Following the operation the head circumference decreased from $41 \mathrm{~cm}$. to $40 \mathrm{~cm}$., and the bulging fontanelle subsided, but the child's general condition remained poor and it continued stubbornly to refuse food. 
On January 31 , eight days after the operation, the bulging of the fontanelle reappeared, the head circumference increased to $42 \mathrm{~cm}$., the fontanelle measured $7 \times 7 \mathrm{~cm}$. A lumbar puncture yielded little fluid under low pressure. The child's condition rapidly deteriorated, and she died on February 2.

Necropsy (Professor M. Wolman, Department of Pathology, Hebrew University-Hadassah Medical School). At autopsy, evidence of extreme malnutrition, and signs of the above-described operation were noted. The peritoneal cavity contained $180 \mathrm{ml}$. of chylous fluid.

BraIN. Externally, the membranes of the lower part of the brain were markedly thickened and gelatinous. The gelatinous part stretched from the sella turcica to the anterior aspect of the pons and continued down to the spinal cord. The arachnoid of the cisterna magna was most markedly thickened and contained greyish patches $2-4 \mathrm{~mm}$. in diameter, and about $1 \mathrm{~mm}$. in thickness. Coronal sections through the brain showed severe internal hydrocephalus, most marked in the lateral ventricles with thinning of the brain cortex to between $2-8 \mathrm{~cm}$. The third ventricle was found filled with a gelatinous mass adherent on all sides to the walls except for its upper part (Fig. 1). The mass was greyish and homogeneous, was not sharply demarcated from the brain tissue of the hypothalamic regions, and was continuous with the meninges. The tumour occupied the middle portion of the third ventricle and did not invade the posterior part and the pineal recess. The fourth ventricle and the Sylvian aqueduct were not enlarged.

Microscopic Structure of THE Tumour (Fig. 2). The microscopic structure of the tumour differed in the various areas. In some places it had a net-like appearance with small compact nuclei, spheroidal or oval, often lobulated or twisted, surrounded by eosinophilic cytoplasm (Fig. 3). Delicate dendritic processes, with little arborization, emerged from the cytoplasm of some of these cells and gave the tissue its reticular appearance. Between these processes capillaries and thin collagen bundles were found. The tissue space between the processes did not stain. In phosphotungstic-acidhaemotoxylin-stained sections most processes stained purple.

In other areas the tumour was much more cellular (Fig. 4). The cells had mostly vesicular, fusiform nuclei with rounded ends. Most of the chromatin was situated at the nuclear membrane. The cytoplasm of these cells was scanty and stained lightly with eosin. From both ends of the cytoplasm emerged long, delicate processes with very little arborization. In some places the tissue appeared loose with few cells and with a polar arrangement of the nuclei which lay parallel to each other. In these areas the amount of blood vessels and collagen was small.

The tumour infiltrated the brain tissue without clear demarcation and in the infiltrated tissue a marked gliotic reaction was present. In the meninges the tumour infiltrated the proliferated connective tissue of the leptomeninges.

The two main types of cells in this tumour could be identified as piloid astrocytes and oligodendrocytes ; accordingly the tumour was considered to be a mixed astrocytoma and oligodendroglioma.

\section{Discussion}

The presenting sign of the case reported here was an obstinate anorexia with subsequent lack of weight gain which existed from birth until the child's death at the age of almost 6 months. At the age of $4 \frac{1}{2}$ months, signs suggestive of a space-occupying intracranial lesion appeared. At autopsy an astrocytoma, presumably originating in the hypothalamus and extending into and blocking the third ventricle, was found. Since during life and at autopsy no other functional or organic abnormalities were detected, a causal relationship between the hypothalamic lesion and the anorexia had to be assumed.

The role of central nervous centres in the pathogenesis of emaciation has been acknowledged for some time. Gull (1874) described a syndrome of extreme inanition due to a morbid mental state which he termed anorexia nervosa and which is to date by some attributed to hypothalamic lesions. On clinical grounds, anorexia nervosa can hardly be differentiated from Simmonds' pituitary cachexia. The latter disease entity which commonly arises from adenohypophyseal failure was later found to occur also in patients with an intact pituitary, but with tumours or inflammatory processes in the region of the third ventricle (Richardson, 1939; Glanzmann and Wegelin, 1942). The claim that the same symptomatology may be produced by disturbances in any part of the functional unit pituitary-hypothalamus (Zondek, 1923) therefore seems perfectly justified. It is substantiated by experimerital observations to the effect that both hypophysectomy (Paulesco, 1907; Smith, 1927) and hypothalamic lesions (Bailey and Bremer, 1921) may lead to profound cachexia.

Russell (1951, 1957) described a syndrome presenting in infancy or early childhood with severe emaciation despite an initially normal or even enhanced food intake, and accompanied by locomotor hyperactivity, over-alertness or even euphoria, initial growth acceleration, hypotension and hypoglycaemia. Hypothalamic tumours, almost always astrocytomas, were established as the pathological basis of the morbid phenomena. The emaciation was attributed to an abnormal energy expenditure resulting mainly from hyperactivity and hypermetabolism.

The present case resembles the syndrome described by Russell with regard to age, the presenting clinical manifestation, emaciation, and the source and 


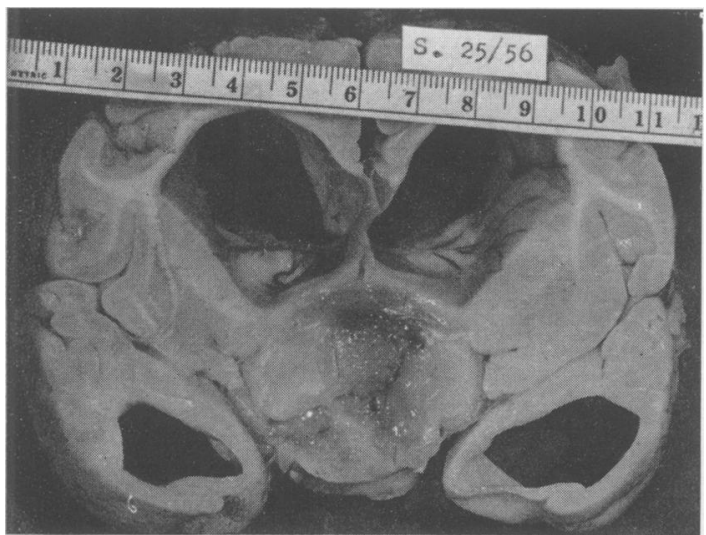

FIG. 1.-Coronal section through brain showing internal hydrocephalus and tumour mass filling dilated third ventricle.

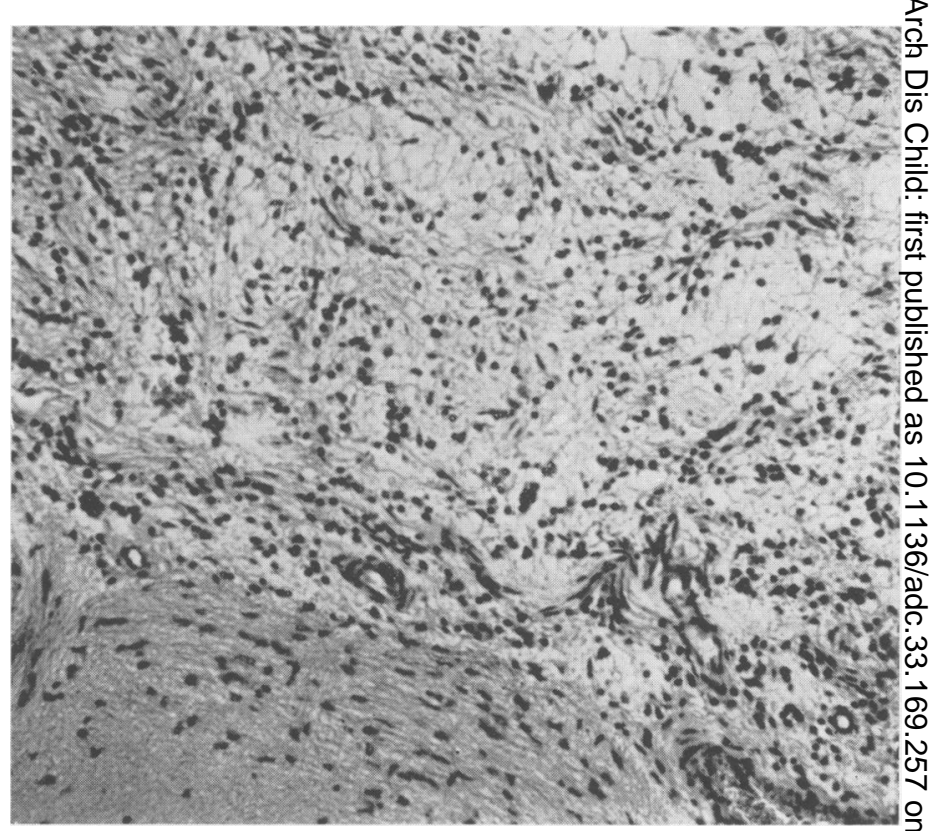

FIG. 3.-Tumour infiltration of meninges, showing net-like appearance of tumour with spongy areas surrounded by more compact bands. At bottom, surface of medulla. $\mathrm{H}$ and $\mathrm{E} . \times 140$.

in bundles with many dilated capillaries. H. and E. $\times 150$.

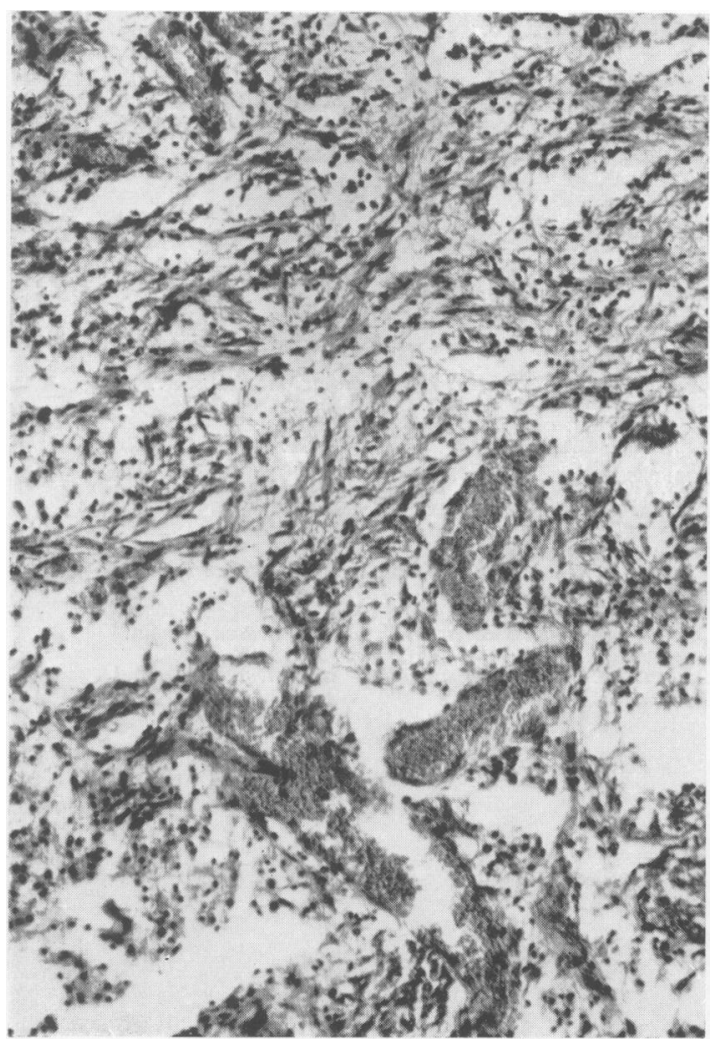

Fig. 4.-A highly cellular area of tumour consisting almost entirely of fibrillary astrocytes.

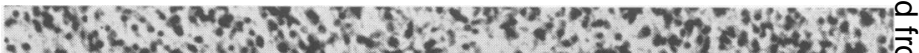
10.

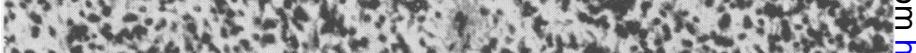

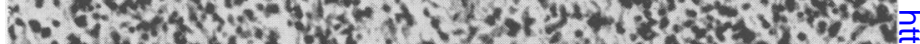

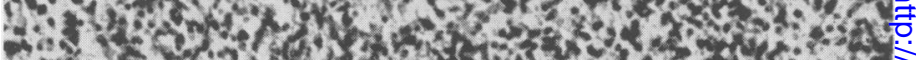

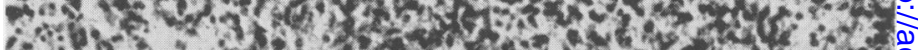

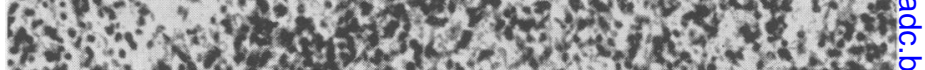

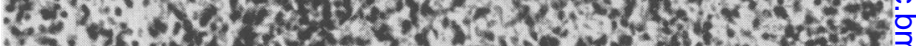

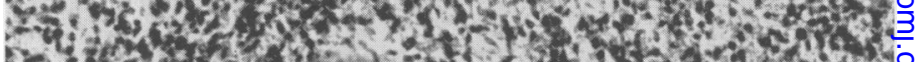

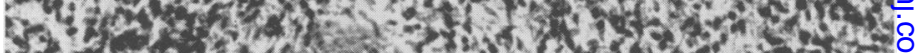

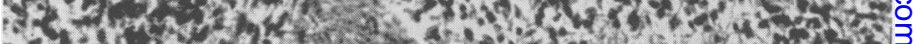

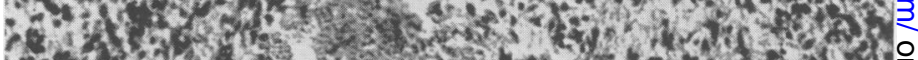

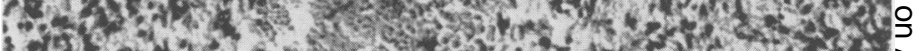

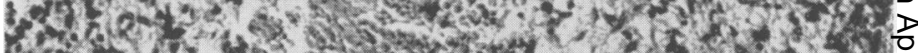
If 2 .

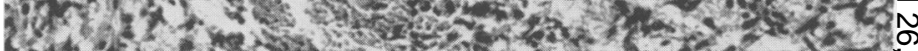

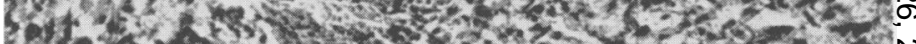

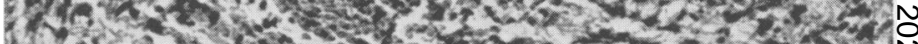

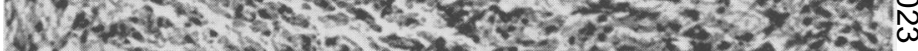

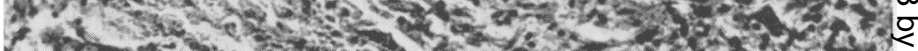

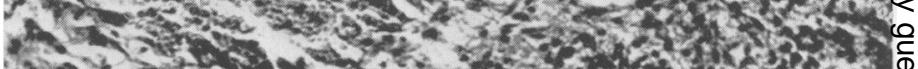

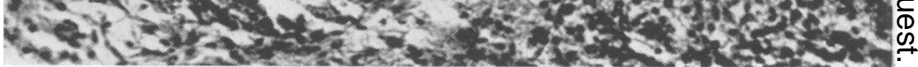


nature of the underlying pathological lesion. However, it differs from Russell's syndrome by the absence of the accompanying clinical criteria of the lesion and the presence of a very marked anorexia which dominated the symptomatology from the very beginning. Consequently it should be regarded as another variety of the multiple hypothalamic syndromes known to exist.

Hypothalamic obesity has been studied, both clinically and experimentally, much more extensively than hypothalamic emaciation. An essential mechanism of both was recently clarified by Brobeck and his group (Brobeck, Tepperman and Long, 1943; Anand and Brobeck, 1951). Electrolytic lesions in the ventromedial nuclei of the hypothalamus produced in rats and cats voracious hunger and subsequent obesity, whilst bilateral lesions in the extreme lateral portions of the lateral hypothalamus inhibited food intake to the point of starvation. It may be assumed that damage to hypothalamic feeding centres may also upset the delicately balanced regulation of food intake in man. Cases are on record in which the appearance of uncontrollable hunger with associated weight gain or of complete anorexia with associated weight loss could be causally related to hypothalamic lesions (Heaney, Eliel, Joel and Stout, 1954; Zondek and Leszynsky, 1956). Heaney's report concerned a child suffering from lymphatic leukaemia who suddenly developed voracious hunger and gained $4 \mathrm{~kg}$. in 20 days. Necropsy revealed a leukaemic infiltrate in the hypothalamus. This case may well be regarded as the counterpart of our present one and both as clinical reflections of Brobeck's animal experiments.

Regardless of these theoretical considerations we may conclude that hypothalamic tumours should be suspected in infants and young childen in whom a thorough clinical investigation fails to account for a failure to gain weight, or for the onset of sudden weight loss, with or without accompanying anorexia. As Russell pointed out, a long time may elapse before the growing tumour produces signs of increased intracranial tension or other neurological signs. In the present case the cerebral nature of the disease process was unfortunately not suspected until the tumour had obstructed the third ventricle.
From a perusal of the literature it appears that this patient is the youngest patient with an astrocytoma on record. The youngest patient recorded in a series studied by Zuelch (1956) was 4 years old when the first symptoms appeared, while Russell's youngest patients were 3 months of age. In the present case complete lack of appetite with resulting failure to gain weight was evident from birth, and it may be concluded that the astrocytoma was of a congenital nature.

\section{Summary}

The case is reported of an infant who suffered from birth from severe anorexia with subsequent failure to gain weight. At the age of $4 \frac{1}{2}$ months signs referable to an internal hydrocephalus appeared, which were only temporarily relieved by drainage of the subarachnoidal space into the peritoneal cavity. About a month later the child died. Autopsy revealed an astrocytoma originating in the hypothalamus and extending into and finally blocking the third ventricle.

In view of the persistence of anorexia since birth and the absence of any other cause either during life or at autopsy it is postulated that the astrocytoma was congenital in nature.

I wish to thank Professor H. Zondek and Dr. J. Leszynsky for their advice, and Professor M. Wolman for the pathological-anatomical examination.

\section{REFERENCES}

Anand, B. K. and Brobeck, J. R. (1951). Proc. Soc. exp. Biol. (N.Y.), 77, 323.

Bailey, P. and Bremer, F. (1921). Arch. intern. Med., 28, 773. Yale J. Biol. Med., 15, 831 .

Glanzmann, E. and Wegelin, C. (1942). Schweiz. med. Wschr., 72, 1401 .

Gull, W. (1874). Trans. clin. Soc. Lond., 7, 22.

Heaney, R. P., Eliel, L. P., Joel, W. and Stout, H. (1954). J. clin. Endocr., 14, 829.

Paulesco, N. Ċ. (1907). J. Physiol. Path. gén., 9, 441.

Paulesco, N. C. (1907). J. Physiol. Path. gen., 9, 441

Richardson, H. B. (1939). Arch. intern. Med., 63, 1. A. A. (1951). Proceedings 22nd Meeting
Association. Arch. Dis. Childh., 26, 274. (1957). Extract from Excerpta med. Sect. VIII Sixth Internat. Congr. neurol. (Bruss.), 1957.

Smith, P. E. (1927). J. Amer. med. Ass., 88, 158.

Zondek, H. (1923). Die Krankheiten der endokrinen Drüsen. Berlin. and Leszynsky, H. E. (1956). Brit. med. J., 1, 197.

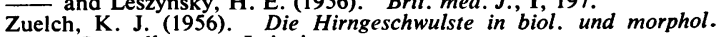
Darstellungen. Leipzig. 